\title{
Protistan community patterns within the brine and halocline of deep hypersaline anoxic basins (DHABs) in the eastern Mediterranean Sea
}

Virginia Edgcomb ${ }^{1}$, William Orsi ${ }^{2}$, Chesley Leslin ${ }^{2}$, Slava S. Epstein ${ }^{2}$, John Bunge $^{3}$, Sunok Jeon ${ }^{3}$, Michail M. Yakimov ${ }^{4}$, Anke Behnke ${ }^{5}$, Thorsten Stoeck ${ }^{5^{*}}$

${ }^{1}$ Department of Geology and Geophysics, Woods Hole Oceanographic Institution, Woods Hole, MA 02543

${ }^{2}$ Biology Department, Northeastern University, Boston, MA 02115

${ }^{3}$ Department of Statistical Science, Cornell University, Ithaca, NY 14853

${ }^{5}$ Institute for Coastal Marine Environment (IAMC), CNR, I-98122 Messina, Italy

${ }^{5}$ Department of Biology, University of Kaiserslautern, D-67663 Kaiserslautern, Germany

${ }^{*}$ Corresponding author:

address: Erwin Schrödinger Str. 14

e-mail:_stoeck@rhrk.uni-kl.de

phone: $\quad$ +49 631-2052502

fax: $\quad$ +49631-2052502

Non-standard abbreviations:

DHAB - deep hypersaline anoxic basin

UMA - uncultured marine alveolate clade 


\begin{abstract}
Environmental factors restrict the distribution of microbial eukaryotes but the exact boundaries for eukaryotic life are not known. Here we examine protistan communities at the extremes of salinity and osmotic pressure, and report rich assemblages inhabiting Bannock and Discovery, two deep-sea superhaline anoxic basins in the Mediterranean. Using a rRNA-based approach, we detected 1538 protistan rRNA gene sequences from water samples with total salinity ranging from $39 \mathrm{~g} / \mathrm{kg}$ to $280 \mathrm{~g} / \mathrm{Kg}$, and obtained evidence that this DNA was endogenous to the extreme habitats sampled. Statistical analyses indicate that the discovered phylotypes represent only a fraction of species actually inhabiting both the brine and the brine-seawater interface, with as much as $82 \%$ of the actual richness missed by our survey. Jaccard indices (e.g., for a comparison of community membership) suggest that the brine/interface protistan communities are unique to Bannock and Discovery basins, and share little (0.8-2.8\%) in species composition with overlying waters with typical marine salinity and oxygen tension. The protistan communities from the basins' brine and brine/seawater interface appear to be particularly enriched with dinoflagellates, ciliates and other alveolates, as well as fungi, and are conspicuously poor in stramenopiles. The uniqueness and diversity of brine and brine-interface protistan communities make them promising targets for protistan discovery.
\end{abstract}

Key words: anoxic, brine, community structure, deep-sea, DHAB, hypersaline, molecular diversity, protists 


\section{Introduction}

Explorations of biological diversity under some of the most extreme conditions present in Earth's biosphere will likely lead to the discovery of microorganisms with novel structures and metabolic/physiological capabilities, and will increase our understanding of the extent and characteristics of life on Earth. Deep hypersaline anoxic basins (DHABs) in the Mediterranean and Red Sea have provided exciting new insights into novel microbial diversity and have already extended our knowledge of the environmental factors that define the limits of life (Eder et al. 2001; Eder et al. 1999; Eder et al. 2002; Sass et al. 2001; van der Wielen et al. 2005; van der Wielen and Heijs 2007; Yakimov et al. 2007b). Several DHABs (Tyro, Urania, Bannock, l'Atalante and Discovery), which originated from the dissolution of ancient subterranean Miocene salt deposits that became exposed to seawater in response to tectonic activity, have been discovered only relatively recently in the Eastern Mediterranean Sea (Camerlenghi 1990; de Lange et al. 1990). These basins are typically more than $3000 \mathrm{~m}$ below sea level, and the high density of the brines within these basins results in limited mixing with overlying seawater. The combination of nearly saturated salt concentration and corresponding high density, high hydrostatic pressure, absence of light, anoxia, and a sharp chemocline make these basins some of the most extreme habitats on Earth.

Each of the Eastern Mediterranean DHABs is geochemically distinct (van der Wielen et al. 2005). For example, a striking difference between the Discovery basin and the other basins is the extremely high concentration of $\mathrm{Mg}^{2+}$ (up to $5000 \mathrm{mM}$ compared to $300-650 \mathrm{mM}$ in the other basins, and ca. $60 \mathrm{mM}$ in regular seawater) and low concentration of $\mathrm{Na}^{+}$(ca.70 mM compared to $3500-4700 \mathrm{mM}$ in the other basins and ca. $500 \mathrm{mM}$ in regular seawater). Such concentrations of divalent cations are the highest recorded to date in a natural environment (Wallmann et al. 2002; Wallmann et al. 1997) and are considered anathema to life and biogeochemical dead ends (Coleman 1993; Horowitz et al. 1972; Oren 1999; Siegel et al. 1979) 
(Coleman 1993; Horowitz et al. 1972; Oren 1999; Siegel et al. 1979). Yet, studies of prokaryotes in the Discovery, L'Atalante, Urania, and Bannock basins incorporating DAPI counts, analyses of $16 \mathrm{~S}$ ribosomal RNA (16S rRNA) gene sequences, and measurements of sulfate reduction, methanogenesis, and heterotrophic activity have revealed metabolically active bacterial and archaeal communities in the Eastern Mediterranean DHABs (Daffonchio et al. 2006; Hallsworth et al. 2007; van der Wielen et al. 2005; van der Wielen and Heijs 2007; Yakimov et al. 2007a; Yakimov et al. 2007b). The unique nature of these microbial communities in the Eastern Mediterranean deep-sea brines became evident by the observation that 16S rRNA gene sequences found in the brines are related to phylogenetic groups that are not found in normal seawater (van der Wielen et al. 2005). Furthermore, in a cluster analysis of archaeal and bacterial $16 S$ rRNA gene data, van der Wielen et al. (2005) revealed distinctive structural differences between the microbial communities in the Urania, Bannock, L'Atalante and Discovery basin, with the latter being the most dissimilar. These data indicated that microbial community structures in the DHABs and geochemical conditions are directly linked. The authors assumed that the distinct geochemical conditions in each of the basins together with their physical separation from each other, as well as their existence for thousands of years resulted in the evolution of specific microbial communities in each of the basins. This assumption finds support in the discovery of novel microbial enzymes with unusual structures and biochemical characteristics that are adapted to function in these basins (Ferrer et al. 2005).

Thus far, the above hypothesis has gone untested for the eukaryote representatives of microbial communities (protists). In chemosynthetic (anoxic) deep-sea systems a high abundance of bacteria usually supports a secondary food web (Taylor et al. 2006; Taylor et al. 2001) that consists of a diverse assemblage of unicellular eukaryotes (Stoeck et al. 2006; Stoeck et al. 2003b). However, protists in deep-sea brines, specifically in $\mathrm{MgCl}_{2}$-rich environments, are entirely unexplored. Despite the fact that protists play an integral role in the 
functioning of any ecosystem (Azam et al. 1983), only a limited number of studies, most of them microscopy-based, have focused on protistan diversity in hypersaline habitats in general. The emerging picture, as summarized in a recent review (Hauer and Rogerson 2005), is that moderately hypersaline systems sustain a rich and diverse community of mostly halotolerant microbial eukaryotes; however, once the salinity exceeds $30 \%$, protists are either missing or very rare (Elloumi et al. 2006; Oren 2000; Pedrós-Alió et al. 2000; Por 1980; RamosCormenzana 1991) (for criticism see (Finlay 1990). In this study, we used statistical and phylogenetic analyses of eukaryote small subunit ribosomal RNA (SSU rRNA) genes to address the following questions: (i) Are there signs of microeukaryotic life in the super-extreme environments of the Bannock and Discovery basins? (ii) If so, is this life represented by a few potentially highly specialized (endemic) taxa or is it as diverse and abundant as in other, nonhypersaline, marine environments? And (iii), do the distinct biogeochemical characteristics of the two basins under study select for different protistan communities?

\section{Materials and methods}

Sample collection and preparation

Samples were collected in fall 2003 aboard the R/V Urania from (a) the Bannock brine/seawater interface (cast $\mathrm{AB} 27 \mathrm{SCl}, 34^{\circ} 17.488^{\prime} \mathrm{N}, 20^{\circ} 00.692^{\prime} \mathrm{E}$ ) with total salinity up to $246 \mathrm{~g} / \mathrm{kg}\left(3.07 \mathrm{~mol} / \mathrm{kg}\right.$ of $\mathrm{Na}^{+}$and $470 \mathrm{mmol} / \mathrm{kg}$ of $\mathrm{Mg}^{2+}$ ); (b) Bannock brine (cast AB29SCl, $34^{\circ} 17.397^{\prime} \mathrm{N}, 20^{\circ} 00.709^{\prime} \mathrm{E}$ ) with total salinity of $280 \mathrm{~g} / \mathrm{kg}$ in Bannock basin (3.50 mol/ $\mathrm{kg}$ of $\mathrm{Na}^{+}$and $540 \mathrm{mmol} / \mathrm{kg}$ of $\mathrm{Mg}^{2+}$ ); and (c) from the Discovery brine/seawater interface (cast DISC3R1, $35^{\circ} 16.611^{\prime} \mathrm{N}$, $21^{\circ} 41.384^{\prime} \mathrm{E}$ ) with total salinity up to $320 \mathrm{~g} / \mathrm{kg}\left(45 \mathrm{mmol} / \mathrm{kg}\right.$ of $\mathrm{Na}^{+}$and 3.30 $\mathrm{mol} / \mathrm{kg}$ of $\mathrm{Mg}^{2+}$ ). Two reference samples were collected from overlying seawater in the DHAB area $\left(34^{\circ} 13.850^{\prime} \mathrm{N}, 21^{\circ} 28.400^{\prime} \mathrm{E}\right)$ with $39 \mathrm{~g} / \mathrm{kg}$ of total salinity (420 
$\mathrm{mmol} / \mathrm{kg}$ of $\mathrm{Na}^{+}$and $55 \mathrm{mmol} / \mathrm{kg} \mathrm{Mg}^{2+}$ ). For a detailed physico-chemical description of the sampling sites we refer to the available literature (Daffonchio et al. 2006; Hallsworth et al. 2007; van der Wielen et al. 2005). To prevent mixing and perturbation of the samples, we applied a specific high-precision sampling technique that was developed for this particular purpose (Daffonchio et al. 2006). This strategy employed the Modus-Scipack system as described in detail previously (Daffonchio et al. 2006) equipped with a CTD and a series of 10-I Niskin bottles as well as a pressure sensor for recording the pressure at which the Niskin bottles were closed. As the halocline samples in the Niskin bottles exhibited a steep salinity gradient, the contents of the Niskin bottles were carefully fractionated on board ship by slowly recovering only the fraction that matched the salinity of the upper or lower halocline (fractionated sampling). For details see Daffonchio et al. (2006). Water samples were filtered through 47-mm diameter, 0.22- $\mu \mathrm{m}$ pore-size Nuclepore filters (Millipore, Billerica, MA, USA). Collected material was re-suspended in $100 \mu \mathrm{l}$ of TE buffer ( $\mathrm{pH}$ 8.0) containing lysozyme $\left(5 \mathrm{mg} \mathrm{ml}^{-1}\right.$ ), lysed by addition of $300 \mu \mathrm{l}$ of lysis buffer QRL1 (Qiagen, Milan, Italy) and stored at $-20^{\circ} \mathrm{C}$ until processing. Total genomic DNA was extracted from filters using a Qiagen RNA/DNA Mini Kit (Qiagen, Milan, Italy). The extraction was carried out according to the manufacturer's instructions. DNA was stored in isopropanol at $-20^{\circ} \mathrm{C}$ before precipitation. The quality of the DNA samples was examined by agarose electrophoresis and concentrations were determined using a NanoDrop ${ }^{\circledR}$ ND-1000 Spectrophotometer (Wilmington, DE, USA).

18S rRNA gene analysis

PCR amplification of the 18S rRNA gene was performed using a nested PCR. The first reaction used the universal eukaryotic primer set EukA 1 to 21 and EukB 1795 to 1772 (Medlin et al. 1988) and HotStar Taq DNA polymerase (Qiagen, Valencia, Calif.). The PCR protocol consisted of an initial hot-start incubation of $15 \mathrm{~min}$ at $95^{\circ} \mathrm{C}$ followed by 30 identical amplification cycles $\left(94^{\circ} \mathrm{C}\right.$ 
for $1 \mathrm{~min}, 55^{\circ} \mathrm{C}$ for $30 \mathrm{~s}, 72^{\circ} \mathrm{C}$ for $2 \mathrm{~min} 30 \mathrm{~s}$; and finally $72^{\circ} \mathrm{C}$ for $10 \mathrm{~min}$ ). This was followed by amplification using the primer combinations Euk360FE and the universal primer 1492R (Medlin et al. 1988). Negative control reactions included bacterial (Escherichia coli) and archaeal (Sulfolobus solfataricus) DNA. For the second PCR amplification, $1 \mu \mathrm{l}$ of the first PCR mixture was used to amplify the target fragments using the same PCR protocol as described above. Amplified DNA was checked for quality by agarose gel electrophoresis, and cloned into the vector TopoXL (Invitrogen). Separate clone libraries were generated for each of the original DNA samples. Plasmid DNA from four 96-well plates of clones from each library (ten 96 well-plates in case of the Bannock library) was prepared using a MWG Biotech RoboPrep2500, and inserts were sequenced bidirectionally using an Applied Biosystems 3730XL capillary sequencer at the Josephine Bay Paul Center at the Marine Biological Laboratory (MBL), Woods Hole, MA. Processing of the data used PHRED, PHRAP (Ewing and Green 1998; Ewing et al. 1998) and a pipeline script to call bases from chromatograms, perform quality control procedures including checks for data consistency, data integrity, and data quality, to trim vector and low quality data and to assemble the sequences into contigs. The sequences were checked for chimeras using the Bellerophon Chimera Check program and the Check_Chimera utility (Ribosomal Database Project (Cole et al. 2003). After removal of short sequences ( $<800$ bp) and putative chimeras, the remaining sequences were clustered using an all-toall sequence comparison at percent similarity cutoffs ranging from $99 \%$ to $50 \%$ as described previously (Stoeck et al. 2007). We selected the OTUs at $98 \%$ for further phylogenetic analysis, and for each such OTU designated one, randomly chosen sequence as a representative. These representative sequences were subsequently aligned to $18 \mathrm{~S}$ rRNA sequences available in the ARB package ((Ludwig et al. 2004), http://www.arb-home.de). The rRNA alignment was corrected manually according to secondary structure information and alignment uncertainties were omitted. Only unambiguously aligned positions were used to construct phylogenetic trees. These sequences have been deposited in Genbank under the accession numbers FJ000071-FJ000279. 
Phylogenetic analyses

Partial alignments comprising sequences of defined taxonomic groups were exported from ARB for phylogenetic analyses to construct detailed subtrees. Evolutionary distance analyses under maximum likelihood criteria were carried out in PAUP* V4.0b8 (Swofford 2002), with all characters equally weighted and unordered. The TBR heuristic option was used to search tree space, running ten random additions with the MulTree option on. The evolutionary model that best fit each of our aligned data sets was chosen among 56 possible models using Modeltest (Posada and Crandall 2001). Support for the evolutionary distance analyses under maximum likelihood came from 1000 bootstrap replicates using heuristic searches. Bayesian analyses were carried out using MrBayes v3.2.1 (Huelsenbeck and Ronquist 2001) with posterior probability support values calculated using four chains/two runs and running 10 million generations for each alignment. Trees were sampled every 1000th generation. The first $25 \%$ of sampled trees were considered 'burn-in' trees and were discarded. A 50\% majority rule consensus of the remaining trees was used to calculate posterior probability values. The $G T R+I+G$ evolutionary model was estimated using hLTR in MrModeltest v2.

Phylotype richness estimates

We estimated the total number of phylotypes (operational taxonomic units) in each sampled community using statistical procedures described previously (Hong et al. 2006; Jeon et al. 2006; Zuendorf et al. 2006). In brief, we fit seven candidate parametric abundance models to the observed phylotype frequency counts, selecting a preferred model based on the Pearson chi-square and Akaike Information Criterion (AIC) statistics, to obtain a final parametric richness estimate and associated standard error (SE). The candidate abundance distributions included the equal-species-sizes model, and the gamma, lognormal, 
Pareto, inverse Gaussian, and mixtures of two and of three exponential distributions. The corresponding mixed-Poisson distributions (e.g., the gammamixed Poisson) were fitted to the frequency count data (derived from the clone libraries) via maximum likelihood, using custom software on the Velocity Cluster in Cornell's Center for Advanced Computing. The selected parametric model in each case is given in Table 1 . We also computed various nonparametric statistics using the software SPADE (Chao and Shen 2003-2005), particularly the Abundance-based Coverage Estimators (of total richness) ACE and ACE1; either ACE or ACE1 was selected as the preferred nonparametric analysis based on an empirical cutoff value for the coefficient of variation of the frequency count data, as given in the literature (Chao and Shen 2003-2005). The selected nonparametric estimator in each case is given in Table 1.

Community similarity

The program package SPADE (Chao and Shen 2003-2005) was used to calculate the Jaccard index as a measure of similarity between two communities based on incidence ( $\mathrm{J}_{\text {incidence}}$ ), abundance ( $\mathrm{J}_{\text {abundance }}$ ), and abundance with adjustment for the effect of unseen shared phylotypes, in order to reduce bias due to undersampling ( $\left.\mathrm{J}_{\text {adjusted }}\right)$ (Chao et al. 2006).

DNA recovery experiments

We considered the possibility that brine DNA may be exogenous, settling from the overlying water with e.g. dead cells and/or detrital material. This possibility was tested in a laboratory experiment designed to replicate as closely as possible the interface between the Bannock brine and the overlying seawater. We prepared artificial seawater with chemistry matching that of the Bannock brine (Daffonchio et al. 2006; van der Wielen et al. 2005). Fifteen liters of this brine solution was put into each of four 25L carboys. Two duplicated experimental treatments included brine solution that was carefully over-layered 
with either $5 \mathrm{~L}$ of water containing live protists (5000 cells/L of Paramecium), or $5 \mathrm{~L}$ of artificial seawater containing DNA from dead cells (5000 cells/ $L$ of heatkilled Paramecium heated to $60^{\circ} \mathrm{C}$ for $30 \mathrm{~min}$ ). In the absence of actual counts, we chose this cell abundance as representative of in situ conditions because heterotrophic protists are typically found in 1:1000 ratio to their principal (prokaryotic) prey (Zubkov et al. 2007); the latter is about $5 \times 10^{4} \mathrm{ml}^{-1}$ in waters adjacent to Bannock's brine (Daffonchio et al. 2006; van der Wielen et al. 2005). Continuous separation of the two layers was confirmed by regular measurements of salinity and density of the upper (3\% salinity) and lower (the brine) layers. One carboy from each treatment was sacrificed immediately $\left(T_{0}\right)$, and the two remaining carboys were sacrificed after 6 weeks of incubation $\left(T_{1}\right)$, by collecting two $5 \mathrm{~L}$ samples of the brine layer by carefully dripping the brine solution from the bottom of the carboy into sterile flasks. Additionally, two $500 \mathrm{ml}$ samples of the overlaying seawater were collected from each carboy, and two 500-ml halocline samples at $T_{1}$. The brine samples from each carboy were individually filtered on $0.22 \mu \mathrm{m}$ Nucleopore filters, and DNA was extracted using the same protocol as was used during the original sample collection in the field. This was followed by PCR amplification of 18S rRNA genes using the same protocol as above.

\section{Results and discussion}

The principal purpose of this study is to answer the following three questions: (i.) Does microeukaryotic life exist at the extremes of salinity and osmotic pressure found in the thalassic pure halite Bannock basin and the athalassic pure bischofite Discovery basin with chaotrophic conditions? (ii.) If yes, is this life diverse and abundant? (iii.) Do the geochemically-distinct basins exhibit similar protistan communities or do they select for different protistan lineages? To address these questions, we explored the protistan communities in these two extreme environments using statistical and phylogenetic analyses of eukaryote rRNA genes retreived from (1.) the interface and (2.) the brine body of Bannock 
basin, (3.) the chaotrophic interface of the Discovery basin, and (4.) a seawater reference sample collected immediately above the haloclines.

I. Does microeukaryotic life exist at the extremes of salinity and osmotic pressure in the Bannock and Discovery basins?

We successfully constructed four SSU rRNA gene clone libraries from the environmental genomic DNA extracts, which supports the notion that eukaryotes are present in all sampled environments, including the extremes of the Bannock brine. We considered a possibility that this DNA was not indigenous to the respective environments. Indeed, the high density of the haloclines of the DHABs may act as a barrier that traps organic material (including cell debris) originating from the upper water column (de Lange et al. 1990), and the high salt concentration of the brine may help preserve DNA (Danovaro et al. 2005). To experimentally check the likelihood of an allochtonous origin for brine and interface DNA, we conducted a mesocosm experiment in which we simulated the deep-seawater, the halocline, and the brine of the Bannock Basin. The experiment was designed to investigate the likelihood of the (i) accumulation of PCR-amplifiable DNA from the overlying seawater in the halocline, and (ii) permeation of such DNA into the brine and its persistence there. Live or heatkilled Paramecium cells were layered above the simulated halocline and incubated for six weeks. Figure $7 \mathrm{a}$ shows that at the start of the experiment positive amplification of eukaryotic genomic DNA was only achieved for the seawater overlayers. After the incubation period, no PCR-amplifiable (same protocol as used for the clone library construction and at the beginning of the mesocosm experiment) DNA was detected in the overlying seawater, the interface or the brine (Fig. 7b).

Even though our experimental setup only approximated the physicochemical conditions at the Bannock interface, and tested a single organism, the data strongly suggest a low probability of PCR contamination from the accumulation of amplifiable extracellular DNA bound to detritus or from the 
accumulation and preservation of intact dead allochtonous planktonic organisms. This is likely due to the specific density of the brine $(1.23$ at $280 \mathrm{~g} / \mathrm{Kg}$ salinity, the highest sampled in this study in the Bannock brine), as detrital particles as a rule have a higher density (Epstein 1995) and should simply sink to the bottom. Allochtonous DNA in the brine should therefore be limited to the transient amount, further diminished by its apparent degradation as indicated by the failure of our PCR reactions (see faint smear of non-amplifiable DNA in Fig. 7b). We assume that the relatively high temperatures in the deep waters of the basins under study (ca. $14{ }^{\circ} \mathrm{C}$ ) fuel a faster degradation of transient high-molecular weight free DNA compared to 'normal' cold deep-sea environments. Live cells on the other hand would not be able to penetrate even the uppermost layers of the interface as their typical specific density is 1.025 (Beaver and Crisman 1982), or less (Gates et al. 1982), and even hard-bodied benthic metazoa are lighter than brine (Epstein 1995). It therefore stands to reason that our samples from at least the denser brines were largely free of allochtonous cells and their DNA, and that at least the vast majority of detected 18S rRNA gene sequences represent the indigenous protistan communities. Despite this reasoning, we note that we cannot exclude detection of non-indigenous or inactive organisms in our DNAderived clone libraries. Evidence for the indigenuous nature of these organisms can only come from direct isolation and culturing or RNA-targeted direct hybridization techniques (Massana et al. 2002; Stoeck et al. 2003a). Therefore, we consider the indigenous nature of the analyzed protistan communities merely as a working hypothesis.

II. How abundant and diverse is protistan life in Bannock and Discovery Basins?

We monitored phylotype accumulation (library saturation) during sequencing. As three of the libraries (Discovery interface, Bannock brine, seawater) were approaching saturation after analyzing ca. 150-200 protistan clones (Fig. 1) we did not continue sequencing these libraries. This was different for the Bannock interface library. Even after the analysis of more than 1500 clones, the phylotype 
accumulation curve is still increasing steeply. Richness estimates revealed that the protistan community is quite diverse within each of the four environments sampled, with predicted numbers of OTUs that are higher in the interface and brine environments than in the overlying seawater. At 95\% sequence similarity parametric estimators predict $103.3 \pm 48$ OTUs in the Bannock interface, 141.8 \pm 83.5 OTUs in the Discovery interface, $119 \pm 64.1$ OTUs in the Bannock brine, and $55.5 \pm 15.2$ OTUs in the overlying seawater control. Nonparametric estimators were consistent with these predictions (Table 1). As estimates for selected cases are too inaccurate (high SE), we here refrain from discussing phylotype richness estimates at higher sequence similarities (e.g. 98\% and 99\%).

A general overview of all sequences (Fig. 2) shows a high diversity: with the exception of excavates and amoebozoa we found representatives of all major eukaryote taxonomic groups (opisthokonts, plants, cercozoa, alveolates, stramenopiles and discicristates). All domain-specific libraries are dominated by sequences that have affiliations to single cell organisms and metazoa play only a negligible role (data not shown). The vast majority of all phylotypes retrieved in this study falls within the alveolates (74\%), $12 \%$ of which are constituted by ciliates and $62 \%$ by dinoflagellates (including syndiniales) and uncultured marine alveolates. Also fungi are very abundant (17\%) while other taxonomic groups like stramenopile (2\%) and euglenozoan (4\%) flagellates as well as Polycystinea (2\%) are relatively rare. This community composition is distinct from the typical picture of open ocean communities in the photic zone that are usually dominated by stramenopiles and pigmented picoplankton taxa (Countway et al. 2007; Massana et al. 2004b; Moon-van der Staay et al. 2001; Not et al. 2007), but largely agrees with observed diversity and total diversity estimates of other molecular protistan diversity surveys in (anoxic) deep-sea environments (Edgcomb et al. 2002; Stoeck and Epstein 2003; Stoeck et al. 2006; Takishita et al. 2007). This further supports the notion that our interface and brine libraries are not primarily reflections of detritus from the water column but at least to a large extent reflects indigenous protistan assemblages. 
III. Are protistan communities from the Bannock and Discovery basins unique?

The phylotypes and diverse taxonomic groups we recovered are not equally distributed in the four samples that we studied, and the number of phylotypes shared between the different samples is only marginal (Table 2). We calculated Jaccard indices as a measure of community similarity (Table 3). Regarding community membership ( $\mathrm{J}_{\text {incidence}}$ ), community structure (Jabundance) and community structure after adjustment for unseen phylotypes ( $\left.\mathrm{J}_{\text {adjusted }}\right)$, a very high dissimilarity (Jaccard values range between 1-0 with 1 indicating identical communities) was found between the Bannock and Discovery interfaces communities (0.015-0.02) (Table 3). A higher similarity was detected in all cases when comparing the seawater reference sample with the two DHABs interface communities. The brine community proved to be most dissimilar from all other communities in all cases. These data show increasing changes in community membership and structure from the deep seawater through the halocline and into the brine. This is in agreement with previous studies on bacterial and archaeal communities in Eastern Mediterranean DHAB's (Daffonchio et al. 2006; van der Wielen et al. 2005; Yakimov et al. 2007b).

Van der Wielen et al. (2005) observed most pronounced differences in bacterial community composition between the Discovery basin and the other DHABs in the Eastern Mediterranean (Urania, Bannock, L'Atalante). The authors attribute this finding to the high concentrations of $\mathrm{MgCl}_{2}$ found in Discovery. Most known and described hypersaline organisms have difficulties coping with high $\mathrm{MgCl}_{2}$ concentrations. $\mathrm{MgCl}_{2}$-rich environments like bittern ponds have even been described as sterile (Javor 1989). The molecular mechanisms that enable protists to cope with extremely high concentrations of divalent cations in their natural habitat are literally unknown (Oren 2002). Different from sodium salts, magnesium salts behave as salting-in salts, increasing protein solubility and reducing protein stability. Clearly, high $\mathrm{MgCl}_{2}$ concentrations seem to impose more of a restriction on microbial life in some of the DHABs due to its chaotropicity (Hallsworth et al. 2007). Thus, it is highly likely that life in the 
Discovery interface requires specific adaptations, resulting in microbial communities that are distinctly different from the ones in $\mathrm{NaCl}$-rich environments like Bannock.

A striking difference in the microeukaryote community composition between the $\mathrm{NaCl}$-rich Bannock and the $\mathrm{MgCl}_{2}$-rich Discovery environments is the distribution of fungal phylotypes. No fungi were detected in the Bannock brine and the Discovery interface, while they are numerous in the Bannock interface library (24 basidiomycetes and ten ascomycetes, one of which is shared with the reference seawater library, clone 572A06). Regarding their adaptation to highsalt environments, fungi, specifically ascomycete yeasts and basidiomycetes, reaffirmed themselves as one of the ecologically most successful eukaryotic lineages (Gunde-Cimerman et al. 2005; Gunde-Cimerman et al. 2000; Kis-Papo et al. 2001). However, this situation is not quite as obvious regarding the adaptation of fungi to anoxia. Apart from a few exceptions (e.g. some chytridiomycetes) no strictly anaerobic fungi have been described and they have been thought to play only a minor role in ecosystem processes in anaerobic systems (Dighton 2003; Mansfield and Barlocher 1993). This contrasts with molecular diversity surveys in anaerobic aquatic environments, where fungal sequences sometimes account for a significant fraction of the clones (Dawson and Pace 2002; Edgcomb et al. 2002; Luo et al. 2005; Stoeck and Epstein 2003; Stoeck et al. 2006; Stoeck et al. 2007). Support for the survival and growth of fungi in anaerobic environments comes from reports of some ascomycetes (Dumitru et al. 2004; Sonderegger et al. 2004) and some basidiomycetes (Fell et al. 2001) that are capable of fermentation and anaerobic growth, some of which have even been isolated from anaerobic deep-sea environments (Nagahama et al. 2003). Thus, we assume that fungi indeed may play an ecologically important role in anoxic hypersaline environments. This assumption needs to be verified in future studies.

In our study, large alveolate sequence clusters are populated almost exclusively by sequences recovered from the Bannock interface and by only a few sequences from the Discovery interface and none from the Bannock brine or 
the reference seawater (Fig. 4). These clusters fall within the Uncultured Marine Alveolates Group II (UMAll). This lineage was originally discovered in the Antarctic deep sea (López-García et al. 2001) and since then, UMAll sequences have been reported from a variety of different marine environments including diverse anoxic deep-sea environments (Edgcomb et al. 2002; López-García et al. 2003; Stoeck et al. 2006; Takishita et al. 2007) but also from oxygenated open ocean or coastal waters (Massana et al. 2004a; Not et al. 2007; Romari and Vaulot 2004; Worden 2006). The closest BLASTn match of all DHAB UMAll sequences exhibiting only $90 \%$ sequence similarity was to two previously deposited sequences of the flagellated parasite Amoebophyra, namely Amoebophyra sp. ex. Gymnodinium instriatum (dinoflagellate) and Amoebophyra sp. ex. Alexandrium affine (dinoflagellate). However, due to the large phylogenetic distance of the environmental DHAB UMAll sequences to Amoebophrya, it is not possible to infer the life styles of these DHAB organisms.

One large clade ("uncultured marine alveolate Bannock clade", Fig. 5) consisting of exclusively Bannok sequences sits as a possible sister group to UMAI, deeply branching with the "true" dinoflagellates and the UMAI. This novel group is also populated by sequences exclusively from the interface in Bannock basin. There is no support for its inclusion in UMA I, in fact different analyses place this clade within the dinoflagellates (with very weak support, unpublished data), rendering the branching position of this clade, and thus, the cellular identity and ecological role of the respective organisms, uncertain. Another environmental clade ("uncultured dinoflagellate clade") is located "between" the "core dinoflagellates" and the UMAll, and includes sequences from uncultured organisms recovered from the nanoplankton size fraction of the deep chlorophyll maximum in the Sargasso Sea (Armbrust et al., unpublished), and a supersulfidic anoxic fjord in Norway (Behnke et al, unpublished, (Behnke et al. 2006). The closest BLASTn hits of these environmental sequences to a described species are to the dinoflagellates Gyrodinium. Like numerous other dinoflagellates, Gyrodinium is characterized as a mixotroph feeding type, that is capable of phagotrophy, and thus, is able to thrive in light-independent environments 
(Stoecker 1999). Neither Bayesian nor Evolutionary Distance offers strong support to hold this group of sequences together or to hold them outside of either the "core" dinoflagellates or UMAIl. Despite weak support within the dinoflagellate analysis for most groupings, Figure 5 illustrates a tremendous diversity of dinoflagellate-like taxa present in the Bannock interface environment, with some obviously specific and possibly endemic Bannock clades.

Analysis of ciliate sequences (Fig. 6) reveals that representatives of this alveolate phylum comprise part of all DHAB communities under study. However, while ciliates were relatively rare in the reference seawater library (4 phylotypes at $98 \%$ sequence similarity), the ciliated protists constitute a significant proportion of the brine library (10 phylotypes at $98 \%$ sequence similarity). We found representatives from six out of eleven described (ribo)classes, with some of them occurring exclusively in a single environment. For example, the strictly anaerobic Armophorea are unique to the chaotrophic Discovery sample, while heterotrichs occur exclusively in the Bannock brine. The vast majority of all ciliate phylotypes discovered in this study branch as closest neighbors of either environmental clones from other marine anoxic sampling sites such as, the Great Sippewisset Saltmarsh (CCW111 and CCA70, (Stoeck and Epstein 2003), the Guaymas deep-sea basin (C1_E007, (Edgcomb et al. 2002), the Mid-Atlantic Ridge (AT6-4, (López-García et al. 2003), and a Danish fjord (M1_18C08, (Zuendorf et al. 2006). The closest related named species are ciliates with a facultative or strict anaerobic or microaerophilic life style, such as, Trimyema, Strombidium, Metopus, and Peritromus. A highly supported clade consisting exclusively of possibly endemic sequences recovered from the thalassic Bannock interface is highly divergent to Cryptocaryon irritans, an enigmatic parasite with a weak assignment to the class Prostomatea (Wright and Colorni 2002). This Bannock clade shares a common ancestor with another environmental sequence IN2411 retrieved from an anoxic deep-sea sediment sample (López-García et al. 2003) and cannot be assigned to one of the eleven described classes, suggesting a possible novel ciliate candidate-class. This finding once more (compare (Behnke et al. 2006; Stoeck et al. 2006; Stoeck et al. 2003b; Zuendorf et al. 2006) 
emphasizes that we are still far from the discovery of all higher taxonomic groups in the domain Eukarya, even in groups of organisms that have been studied for more than two centuries (Ehrenberg 1838; Foissner 2008; Kahl 1930-1935). Specifically, extreme environments that have been difficult to access with traditional cultivation- and microscopy-based techniques repeatedly emerge as a potential excellent source of novel taxa at high taxonomic levels.

\section{Conclusions}

The environmental conditions that define the limits of eukaryote life are still far from being established. Our studied revealed that even in one of the most extreme marine environments that has been considered anathema to life for a long time, a diverse assemblage of protists an be found. This assemblage seems to be supported by a high abundance of bacteria as inferred from the trophic mode of most of the organisms that are related to the 18S rRNA gene sequences retrieved from the Discovery and Bannock DHABs. Considering the high proportion of sequence clades that are unique to the environments under study and their high divergence to previously described 18S rRNA gene sequences, these basins are an excellent source for the discovery of novel organisms with physiological capabilities and survival strategies that are very likely still unknown to science. Our data suggest that the protistan communities in the brine and the brine/seawater interfaces of Bannock and Discovery basins are unique to these habitats and share little similarity in species composition with the overlying seawater. Thus, it seems likely, that as reported for bacteria, the distinct biogeochemical conditions prevailing in the different basins exert a specific selection pressure on protistan communities resulting in the evolution of specialized, possibly geographically restricted, protistan assemblages.

\section{Acknowledgments}


This study was supported by grant grant STO414/2-4 of the Deutsche Forschungsgemeinschaft, the EuroDEEP program of the European Science Foundation under 06-EuroDEEP-FP-004 MIDDLE project and NSF-grant MCB0348341 VE wishes to acknowledge Dr. Hilary Morrison and Rich Fox of the Marine Biological Laboratory, Woods Hole for the development and adaptation of their pipeline scripts for processing the sequence data for this study. We thank Linda Woodard for overseeing the richness calculations. This research was conducted using the resources of the Cornell University Center for Advanced Computing, which receives funding from Cornell University, New York State, the National Science Foundation, and other leading public agencies, foundations, and corporations. We thank the captain and the crew of RV Urania for their expert handling of our casts and equipment and for highly productive oceanographic cruises. 


\section{Figure legends}

Figure 1. SSU rRNA gene protistan phylotype accumulation for the four libraries under study. Since three of the libraries approached saturation after sampling 150-200 clones, we did not perform further clone sampling and analyses. However, one of the libraries (Bannock interface) still increases linearly after sampling 1600 clones. The insert displays the phylotype accumulation for the libraries after 200 random clone selections from the Bannock interface library. Phylotype definition is based on a sequence similarity of $98 \%$. Metazoa are excluded.

Figure 2. Bayesian phylogenetic analysis showing the general distribution of all protistan SSU rRNA gene phylotypes retrieved from the Bannock interface, Discovery interface, Bannock brine and a reference deep seawater community in the DHAB region of the Eastern Mediterranean Sea. The pie chart displays the proportion of phylotypes in major eukaryote taxonomic groups. Metazoa are excluded from these analyses. Four incrementally heated, randomly seeded Markov chains were run for $4 \times 10^{6}$ generations, and topologies were sampled every $100^{\text {th }}$ generation. To confirm these results, 4 independent, randomly seeded analyses of the data set were performed with identical results. The first 15000 generations were discarded as burn-in based on analysis of Bayesian output data. Support values at nodes are Bayesian posterior probabilities observed at $4 \times 10^{6}$ generations, and RAXML maximum likelihood bootstrap values estimated using 1000 bootstrap replicates (version 4.0.2).

Figure 3. Minimum evolution phylogenetic tree of eukaryotic small-subunit rRNA gene sequences showing the position of fungal phylotypes in the Bannock interface (green), Discovery interface (brown), Bannock brine (red) and overlaying oxygenated deep seawater (blue). The tree was constructed under maximum-likelihood criteria by using a GTR+I+G DNA substitution model with the variable-site gamma distribution shape parameter $(G)$ at 0.7780 , the 
proportion of invariable sites at 0.2179 and base frequencies and a rate matrix for the substitution model as suggested by Modeltest (Posada and Crandall 2001) based on 809 unambiguously aligned positions. The first numbers are distance bootstrap values over 50\% from an analysis of 1000 pseudoreplicates. The second numbers are posterior probabilities from 1502 collected trees (2 runs, $10^{6}$ generations, 1000 sampled trees per run, burnin $=250$ ). Black circles at nodes indicate full support from both analyses. Numbers behind a DHAB sequence indicate a phylotype that was observed in both the upper and lower face of the halocline with color coding as described above.

Figure $4 a$ and $b$. Minimum evolution phylogenetic tree of eukaryotic smallsubunit rRNA gene sequences showing the position of uncultured marine alveolate group II (UMAII) phylotypes in the Bannock interface (green), Discovery interface (brown), Bannock brine (red) and overlaying oxygenated deep seawater (blue). The tree was constructed using a Tamura-Nei substitution model with the variable-site gamma distribution shape parameter $(G)$ at 0.5958 , the proportion of invariable sites at 0 and base frequencies and a rate matrix for the substitution model as suggested by Modeltest (Posada and Crandall 2001) based on 1007 unambiguously aligned positions. The first numbers are distance bootstrap values over $50 \%$ from an analysis of 1000 pseudoreplicates. The second numbers are posterior probabilities from 1502 collected trees (2 runs, 10 generations, 1000 sampled trees per run, burnin $=250$ ). Black circles at nodes indicate full support from both analyses. Numbers behind a DHAB sequence indicate a phylotype that was observed in both the upper and lower face of the halocline with color coding as described above.

Figure 5. Minimum evolution phylogenetic tree of eukaryotic small-subunit rRNA gene sequences showing the position of uncultured marine alveolates, dinoflagellates and Syndiniales phylotypes in the Bannock interface (green), Discovery interface (brown), Bannock brine (red) and overlaying oxygenated deep seawater (blue). The tree was constructed under Tamura Nei substitution 
model with the variable-site gamma distribution shape parameter $(G)$ at 0.6935 , the proportion of invariable sites at 0 and base frequencies and a rate matrix for the substitution model as suggested by Modeltest (Posada and Crandall 2001) based on 862 unambiguously aligned positions. The first numbers are distance bootstrap values over 50\% from an analysis of 1000 pseudoreplicates. The second numbers are posterior probabilities from 1502 collected trees ( 2 runs, $10^{6}$ generations, 1000 sampled trees per run, burnin $=250$ ). Black circles at nodes indicate full support from both analyses. Numbers behind a DHAB sequence indicate a phylotype that was observed in both the upper and lower face of the halocline with color coding as described above.

Figure 6. Minimum evolution phylogenetic tree of eukaryotic small-subunit rRNA gene sequences showing the position of ciliate phylotypes in the Bannock interface (green), Discovery interface (brown), Bannock brine (red) and overlaying oxygenated deep seawater (blue). The tree was constructed under maximum-likelihood criteria by using a GTR+I+G DNA substitution model with the variable-site gamma distribution shape parameter $(G)$ at 0.4344 , the proportion of invariable sites at 0.0886 and base frequencies and a rate matrix for the substitution model as suggested by Modeltest (Posada and Crandall 2001) based on 986 unambiguously aligned positions. The first numbers are distance bootstrap values over $50 \%$ from an analysis of 1000 pseudoreplicates. The second numbers are posterior probabilities from 1502 collected trees (2 runs, $10^{6}$ generations, 1000 sampled trees per run, burnin $=250$ ). Black circles at nodes indicate full support from both analyses. Numbers behind a DHAB sequence indicate a phylotype that was observed in both the upper and lower face of the halocline with color coding as described above.

Figure 7. (a) Gel picture at $t_{0}$ top row; (b) gel picture at $t=6$ weeks bottom row. $\mathrm{SW}=$ carboy with seawater overlayer containing live Paramecium, DW=carboy with distilled water overlayer containing heat-killed Paramecium. In order of lanes: 1) BenchTop 1kb DNA ladder (Promega); 2) 528F/1492R positive control 
(Chlamydomonas); 3) 528F/1492R negative control; 4) and 5) 528F/1492R SW overlayer 500ml sampled reps 1 and 2; 6) and 7) 528F/1492R SW brine layer 5L sampled reps 1 and 2; 8) and 9) 528F/1492R DW overlayer 500ml sampled reps 1 and 2; 10) and 11) 528F/1492R DW brine layer 5L sampled reps 1 and 2; 12) 360F/1492R positive control; 13) 360F/1492R negative control; 14) and 15) $360 \mathrm{~F} / 1492 \mathrm{R}$ SW overlayer $500 \mathrm{ml}$ sampled reps 1 and 2; 16) and 17) $360 F / 1492 R$ SW brine layer 5L sampled reps 1 and 2; 18) and 19) 360F/1492R DW overlayer 500ml sampled reps 1 and 2; 20) and 21) 360F/1492R DW brine layer 5L sampled reps 1 and 2; 22) and 23) blanks; 24) BenchTop 1kb DNA ladder. Bottom row is same order for $t=6$ weeks, with the addition of lane 22) 528F/1492R SW halocline bottom 3 liters; 23) 528F/1492R SW halocline next 3 liters; 24) 528F/1492R DW halocline bottom 3 liters; 25) 528F/1492R DW halocline next 3 liters; 26) and 27) blanks; 28) BenchTop 1kb DNA ladder. 
Table 1. Parametric (stochastic abundance model-based) and nonparametric (coverage-based) estimates of number of phylotypes (95\% sequence similarity) for the different protistan communities under study. $\mathrm{BI}=$ Bannock interface, $\mathrm{DI}=$ Discovery interface, $\mathrm{BB}=$ bannock brine, $\mathrm{SW}=$ seawater reference community, $\mathrm{S}=$ estimate, $\mathrm{SE}=$ standard error. Estimates are presented at the $95 \%$ sequence similarity cutoff.

\begin{tabular}{|c|c|c|c|c|}
\hline Site & BI (756)* & $\mathrm{DI}(283)^{\star}$ & $\mathrm{BB}(165)^{\star}$ & SW(334)* \\
\hline Observed & 38 & 39 & 38 & 31 \\
\hline $\begin{array}{l}\text { Total richness, } \\
\text { parametric } \\
\text { estimate } \pm S E\end{array}$ & $103.3 \pm 48$ & $141.8 \pm 83.5$ & $119 \pm 64.1$ & $55.5 \pm 15.2$ \\
\hline $\begin{array}{l}\text { Abundance } \\
\text { model }\end{array}$ & $\begin{array}{l}\text { Two Mixed } \\
\text { Exponential }\end{array}$ & $\begin{array}{l}\text { Inverse } \\
\text { Gaussian }\end{array}$ & $\begin{array}{l}\text { Inverse } \\
\text { Gaussian }\end{array}$ & $\begin{array}{l}\text { Two Mixed } \\
\text { Exponential }\end{array}$ \\
\hline $\begin{array}{l}\text { Total richness, } \\
\text { nonparametric } \\
\text { estimate } \pm S E\end{array}$ & $104.8 \pm 46.7$ & $103.5 \pm 42.9$ & $89 \pm 31.1$ & $42.7 \pm 9.1$ \\
\hline Estimator & ACE-1 & ACE-1 & ACE-1 & ACE-1 \\
\hline
\end{tabular}

*library size (number of clones sequenced) 
Table 2. Phylotypes shared by two or more libraries. DF=dinoflagellates, UMAll=uncultured marine alveolates groups II

\begin{tabular}{lcl}
\hline libraries & n shared phylotypes & Sequences in trees \\
\hline Bannock interface- & 7 & $1041 \mathrm{H09}$ (UMAII), \\
Seawater & $521 \mathrm{B09}$ (UMAll), \\
& $521 \mathrm{B08}$ (DF), \\
& $571 \mathrm{G08}$ (DF), \\
& $521 \mathrm{G06}$ (DF), \\
& $572 \mathrm{A06}$ (fungi), \\
& $1041 \mathrm{E04}$ (ciliates) \\
\hline Discovery interface- & BB1D12 (ciliates), \\
Bannock brine- & 212C04 (ciliates) \\
Seawater & \\
\hline Discovery interface- & \\
Bannock interface- & $571 \mathrm{A05}$ (DF) \\
Seawater & \\
\hline
\end{tabular}


Table 3. Jaccard indices ( $\mathrm{J}$ ) for a comparison of the eukaryote community membership $\left(\mathrm{J}_{\text {incidence}}\right)$, community structure $\left(\mathrm{J}_{\text {abundance }}\right)$ and the community structure under consideration of the unseen phylotypes ( $\left.\mathrm{J}_{\text {adjusted }}\right)$ in the upper and the lower face of the halocline for different phylotype definitions (sequence similarity). Values for Jaccard indices range between 0 and 1 , with the latter indicating identical communities. The analyses are based on a phylotype definition of $98 \%$ sequence similarity.

\begin{tabular}{|c|c|c|c|c|}
\hline & & $\begin{array}{l}\text { Bannock } \\
\text { interface }\end{array}$ & $\begin{array}{l}\text { Discovery } \\
\text { interface }\end{array}$ & $\begin{array}{l}\text { Bannock } \\
\text { brine }\end{array}$ \\
\hline \multirow{4}{*}{ 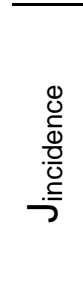 } & Bannock interface & & & \\
\hline & Discovery interface & 0.0159 & & \\
\hline & Bannock brine & 0.0000 & 0.1000 & \\
\hline & Seawater & 0.0534 & 0.1333 & 0.0667 \\
\hline \multirow{4}{*}{ 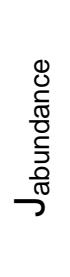 } & Bannock interface & & & \\
\hline & Discovery interface & 0.0203 & & \\
\hline & Bannock brine & 0.0000 & 0.1910 & \\
\hline & Seawater & 0.5892 & 0.2519 & 0.0904 \\
\hline \multirow{4}{*}{ 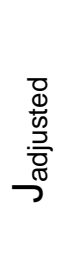 } & Bannock & & & \\
\hline & Discovery & 0.0210 & & \\
\hline & Bannock brine & 0.0000 & 0.1910 & \\
\hline & Seawater & 0.6843 & 0.2519 & 0.0904 \\
\hline
\end{tabular}




\section{References}

Azam F, Fenchel T, Field J, Gray J, Meyer-Reil L, Thingstad F (1983) The ecological role of water column microbes in the sea. Mar Ecol Prog Ser 10:257-263

Beaver JR, Crisman TL (1982) The trophic response of ciliated protozoans in freshwater lakes. Limnol Oceanogr 27:246-253

Behnke A, Bunge J, Barger K, Breiner HW, Alla V, Stoeck T (2006) Microeukaryote community patterns along an $\mathrm{O}_{2} / \mathrm{H}_{2} \mathrm{~S}$ gradient in a supersulfidic anoxic Fjord (Framvaren, Norway). Appl Environ Microbiol 72:3626-3636

Camerlenghi A (1990) Anoxic basins of the eastern Mediterranean: Geological framework. Mar Chem 31:1-19

Chao A, Chazdon RL, Colwell RK, Shen TJ (2006) Abundance-based similarity indices and their estimation when there are unseen species in samples. Biometrics 62:361-371

Chao A, Shen TJ. (2003-2005). http://chao.stat.nthu.edu.tw

Cole JR, Chai B, Marsh TL, Farris RJ, Wang Q, Kulam SA et al. (2003) The Ribosomal Database Project (RDP-II): previewing a new autoaligner that allows regular updates and the new prokaryotic taxonomy. Nucleic Acids Res 31:442-443

Coleman RG (1993). Geological evolution of the Red Sea, vol. 24. Clarendon Press: Oxford, $138 \mathrm{pp}$

Countway PD, Gast RJ, Dennett MR, Savai P, Rose JM, Caron DA (2007) Distinct protistan assemblages characterize the euphotic zone and deep sea $(2500 \mathrm{~m})$ of the western North Atlantic (Sargasso Sea and Gulf Stream). Environ Microbiol 9:1219-1232

Daffonchio D, Borin S, Brusa T, Brusetti L, van der Wielen PW, Bolhuis $\mathrm{H}$ et al. (2006) Stratified prokaryote network in the oxic-anoxic transition of a deep-sea halocline. Nature 440:203-207 
Danovaro R, Corinaldesi C, Dell'Anno A, Fabiano M, Corselli C (2005) Viruses, prokaryotes and DNA in the sediments of a deep-hypersaline anoxic basin (DHAB) of the Mediterranean Sea. Environ Microbiol 7:586-592

Dawson SC, Pace NR (2002) Novel kingdom-level eukaryotic diversity in anoxic environments. Proc Natl Acad Sci U S A 99:8324-8329

de Lange GJ, Middelburg JJ, van der Weijden CH, Catalano G, Luther I, G. W., Hydes DJ et al. (1990) Composition of anoxic hypersaline brines in the Tyro and Bannock Basins, eastern Mediterranean. Mar Chem 31:63-88

Dighton J (2003). Fungi in ecosystem processes, 1st ed., vol. 17. Marcel Dekker Inc.: New York, N. Y.

Dumitru R, Hornby JM, Nickerson KW (2004) Defined anaerobic growth medium for studying Candida albicans basic biology and resistance to eight antifungal drugs. Antimicrob Agents Chemother 48:2350-2354

Eder W, Jahnke LL, Schmidt M, Huber R (2001) Microbial diversity of the brineseawater interface of the Kebrit Deep, Red Sea, studied via 16S rRNA gene sequences and cultivation methods. Appl Environ Microbiol 67:30773085

Eder W, Ludwig W, Huber R (1999) Novel 16S rRNA gene sequences retrieved from highly saline brine sediments of kebrit deep, red Sea. Arch Microbiol 172:213-218

Eder W, Schmidt M, Koch M, Garbe-Schonberg D, Huber R (2002) Prokaryotic phylogenetic diversity and corresponding geochemical data of the brineseawater interface of the Shaban Deep, Red Sea. Environ Microbiol 4:758-763

Edgcomb VP, Kysela DT, Teske A, de Vera Gomez A, Sogin ML (2002) Benthic eukaryotic diversity in the Guaymas Basin hydrothermal vent environment. Proc Natl Acad Sci U S A 99:7658-7662

Ehrenberg CC (1838). Die Infusionstierchen als vollkommene Organismen. Ein Blick in das tiefere organische Leben der Natur. Voss: Leipzig, Germany, $547 \mathrm{pp}$ 
Elloumi J, Carrias J-F, Ayadi H, Sime-Ngando T, Boukhris M, Bouaïn A (2006) Composition and distribution of planktonic ciliates from ponds of different salinity in the solar saltwork of Sfax, Tunisia. Estuar Coast Shelf Sci $67: 21-29$

Epstein SS (1995) Simultaneous enumeration of protozoa and micrometazoa from marine sandy sediments. Aquat Microb Ecol 9:219-227

Ewing B, Green P (1998) Base-calling of automated sequencer traces using Phred. II. Error probabilities. Genome research 8:186-194

Ewing B, Hillier L, Wendl MC, Green P (1998) Base-calling of automated sequencer traces using Phred. I. Accuracy assessment. Genome research 8:175-185

Fell JW, Boekhout T, Fonseca A, Sampaio JP (2001) Basidiomycetous yeast. In: McLaughlin EG and Lemke PA (eds). The mycota: systemics and evolution, 1st edn. Springer: Berlin, Germany

Ferrer M, Golyshina OV, Chernikova TN, Khachane AN, dos Santos VAPM, Yakimov MM et al. (2005) Microbial enzymes mined from the Urania deepsea hypersaline anoxic basin. Chem Biol 12: 895-904

Finlay BJ (1990) Physiological ecology of free-living protozoa. Adv Microbiol Ecol 11:1-34

Foissner W (2008) Diversity and distribution of ciliates (Protista: Ciliophora). Biodivers Conserv 17:345-363

Gates MA, Rogerson A, Berger J (1982) Dry to wet weight biomass conversion constant for Tetrahymena elliott. Oecologia 55:145-148

Gunde-Cimerman N, Oren A, Plemenita^s A (2005). Adaptation to life at high salt concentrations in archaea, bacteria and eukarya. Springer: Dordrecht, The Netherlands, $577 \mathrm{pp}$

Gunde-Cimerman N, Zalar P, de Hoog S, Plemenita^s A (2000) Hypersaline waters in salterns - natural ecological niches for halophilic black yeasts. FEMS Microbiol Ecol 32:235-240 
Hallsworth JE, Yakimov MM, Golyshin PN, Gillion JL, D'Auria G, de Lima Alves F et al. (2007) Limits of life in $\mathrm{MgCl}_{2}$-containing environments: chaotropicity defines the window. Environ Microbiol 9:801-813

Hauer G, Rogerson A (2005) Heterotrophic protozoa from hypersaline environments. In: Gunde-Cimerman N, Oren A and Plemenitas A (eds). Adaptation to life at high salt concentrations in archaea, bacteria, and eukarya. Springer: Dordrecht, The Netherlands. pp 519-540

Hong SH, Bunge J, Jeon SO, Epstein SS (2006) Predicting microbial species richness. Proc Natl Acad Sci U S A 103:117-122

Horowitz NH, Cameron RE, Hubbard JS (1972) Microbiology of the Dry Valleys of Antarctica. Science 176:242-245

Huelsenbeck JP, Ronquist F (2001) MrBAYES: Bayesian inference of phylogenetic trees. Bioinformatics 17:754-755

Javor B (1989). Hypersaline Environments, Microbiology and Biogeochemistry. Springer-Verlag: Berlin

Jeon SO, Bunge J, Stoeck T, Barger K, Hong S-H, Epstein S (2006) Synthetic statistical approach reveals a high degree of richness of microbial eukaryotes in an anoxic water column. Appl Environ Microbiol 72:65786583

Kahl DM (1930-1935). Urtiere oder Protozoa I. Gustav Fischer: Jena, Germany

Kis-Papo T, Grishkan I, Oren A, Wasser SP, Nevo E (2001) Spatiotemporal diversity of filamentous fungi in the hypersaline Dead Sea. Mycol Res 105:749-756

López-García P, Philippe H, Gail F, Moreira D (2003) Autochthonous eukaryotic diversity in hydrothermal sediment and experimental microcolonizers at the Mid-Atlantic Ridge. Proc Natl Acad Sci U S A 100:697-702

López-García P, Rodríguez-Valera F, Pedrós-Alió C, Moreira D (2001) Unexpected diversity of small eukaryotes in deep-sea Antarctic plankton. Nature 409:603-607 
Ludwig W, Strunk O, Westram R, Richter L, Meier H, Yadhukumar et al. (2004) ARB: a software environment for sequence data. Nucleic Acids Res 32:1363-1371

Luo Q, Krumholz LR, Najar FZ, Peacock AD, Roe BA, White DC et al. (2005) Diversity of the microeukaryotic community in sulfide-rich Zodletone Spring (Oklahoma). Appl Environ Microbiol 71:6175-6184

Mansfield SD, Barlocher F (1993) Seasonal variation of fungal biomass in the sediment of a salt marsh in New Brunswick. Microb Ecol 26:37-45

Massana R, Balagué V, Guillou L, Pedrós-Alió C (2004a) Picoeukaryotic diversity in an oligotrophic coastal site studied by molecular and culturing approaches. FEMS Microbiol Ecol 50:231-243

Massana R, Castresana J, Balagué V, Guillou L, Romari K, Groisillier A et al. (2004b) Phylogenetic and ecological analysis of novel marine stramenopiles. Appl Environ Microbiol 70:3528-3534

Massana R, Guillou L, Díez B, Pedrós-Alió C (2002) Unveiling the organisms behind novel eukaryotic ribosomal DNA sequences from the ocean. Appl Environ Microbiol 68:4554-4558

Medlin L, Elwood HJ, Stickel S, Sogin ML (1988) The characterization of enzymatically amplified eukaryotic 16S-like rRNA-coding regions. Gene 71:491-499

Moon-van der Staay SY, De Wachter R, Vaulot D (2001) Oceanic 18S rDNA sequences from picoplankton reveal unsuspected eukaryotic diversity. Nature 409:607-610

Nagahama T, Hamamoto M, Nakase T, Takaki Y, Horikoshi K (2003) Cryptococcus surugaensis sp. nov., a novel yeast species from sediment collected on the deep-sea floor of Suruga Bay. Int J Syst Evol Microbiol 53:2095-2098

Not F, Gausling R, Azam F, Heidelberg JF, Worden AZ (2007) Vertical distribution of picoeukaryotic diversity in the Sargasso Sea. Environ Microbiol 9:1233-1252 
Oren A (1999) Microbiological studies in the Dead Sea: future challenges toward the understanding of life at the limit of salt concentrations. Hydrobiologia 405: $1-9$

Oren A (2000) Diversity of halophilic microorganisms: Environments, phylogeny, physiology, and applications. J Indust Microbiol Biotechnol 28:56-63

Oren A (2002). Halophilic microorganisms and their environments. Kluwer Academic Publishers: Dordrecht, The Netherlands, 575pp

Pedrós-Alió C, Calderón-Paz JI, MacLean MH, Medina G, Marrasé C, Gasol JM et al. (2000) The microbial food web along salinity gradients. FEMS Microbiol Ecol 32:143-155

Por F (1980) A classification of hypersaline waters, based on trophic criteria. Mar Ecol 1: 121-131

Posada D, Crandall KA (2001) Selecting the best-fit model of nucleotide substitution. Syst Biol 50:580-601

Ramos-Cormenzana A (1991) Halophilic organisms and their environment. In: Rodríguez-Valera F (ed). General and applied aspects of halophilic microorganisms. Plenum Press: New York. pp 15-24

Romari K, Vaulot D (2004) Composition and temporal variability of picoeukaryote communities at a coastal site of the English Channel from 18S rDNA sequences. Limnol Oceanogr 49:784-798

Sass AM, Sass H, Coolen MJ, Cypionka H, Overmann J (2001) Microbial communities in the chemocline of a hypersaline deep-sea basin (Urania basin, Mediterranean Sea). Appl Environ Microbiol 67:5392-5402

Siegel BZ, McMurty G, Siegel SM, Chen J, Larock P (1979) Life in the calciumchloride environment of Don-Juan Pond, Antarctica. Nature 280:828-829

Sonderegger M, Jeppsson M, Hahn-Hagerdal B, Sauer U (2004) Molecular basis for anaerobic growth of Saccharomyces cerevisiae on xylose, investigated by global gene expression and metabolic flux analysis. Appl Environ Microbiol 70: 2307-2317 
Stoeck T, Epstein S (2003) Novel eukaryotic lineages inferred from small-subunit rRNA analyses of oxygen-depleted marine environments. Appl Environ Microbiol 69:2657-2663

Stoeck T, Fowle WH, Epstein SS (2003a) Methodology of protistan discovery: from rRNA detection to quality scanning electron microscope images. Appl Environ Microbiol 69:6856-6863

Stoeck T, Hayward B, Taylor GT, Varela R, Epstein SS (2006) A multiple PCRprimer approach to access the microeukaryotic diversity in environmental samples. Protist 157:31-43

Stoeck T, Kasper J, Bunge J, Leslin C, llyin V, Epstein S (2007) Protistan diversity in the arctic: a case of paleoclimate shaping modern biodiversity? PLOS ONE 2: e728

Stoeck T, Taylor GT, Epstein SS (2003b) Novel eukaryotes from the permanently anoxic Cariaco Basin (Caribbean Sea). Appl Environ Microbiol 69:56565663

Stoecker DK (1999) Mixotrophy among dinoflagellates. J Euk Microbiol 46:397401

Swofford DL. (2002). Sinauer Associates Inc.: Sunderland, MA

Takishita K, Yubuki N, Kakizoe N, Inagaki Y, Maruyama T (2007) Diversity of microbial eukaryotes in sediment at a deep-sea methane cold seep: surveys of ribosomal DNA libraries from raw sediment samples and two enrichment cultures. Extremophiles 11:563-576

Taylor GT, Labichella-Armas M, Varela R, Müller-Karger F, Lin X, Scranton MI (2006) Microbial ecology of the Cariaco basin's redoxcline. In: Neretin NL (ed). Past and present water column anoxia. Springer: Dordrecht, The Netherlands. pp 473-499

Taylor GT, Scranton MI, labichella I, Ho T-Y, Thunell RC, Muller-Karger F et al. (2001) Chemoautotrophy in the redox transition zone of the Cariaco Basin: a significant midwater source of organic carbon production. Limnol Oceanogr 46:148-163 
van der Wielen PW, Bolhuis H, Borin S, Daffonchio D, Corselli C, Giuliano L et al. (2005) The enigma of prokaryotic life in deep hypersaline anoxic basins. Science 307:121-123

van der Wielen PW, Heijs SK (2007) Sulfate-reducing prokaryotic communities in two deep hypersaline anoxic basins in the Eastern Mediterranean deep sea. Environ Microbiol 9:1335-1340

Wallmann K, Aghib FS, Castradori D, Cita MB, Suess E, Greinert J et al. (2002) Sedimentation and formation of secondary minerals in the hypersaline Discovery Basin, eastern Mediterranean. Mar Geol 186:9-28

Wallmann KJ, Suess E, Westbrook GH, Winckler G, Cita MB (1997) Salty brines on the Mediterranean sea floor. Nature 387:31-32

Worden AZ (2006) Picoeukaryote diversity in coastal waters of the Pacific Ocean. Aquat Microb Ecol 43:165-175

Wright AD, Colorni A (2002) Taxonomic re-assignment of Cryptocaryon irritans, a marine fish parasite. Europ J Protistol 37:375-378

Yakimov MM, Giuliano L, Cappello S, Denaro R, Golyshin PN (2007a) Microbial community of a hydrothermal mud vent underneath the deep-sea anoxic brine lake Urania (eastern Mediterranean). Orig Life Evol Biosph 37:177188

Yakimov MM, La Cono V, Denaro R, D'Auria G, Decembrini F, Timmis KN et al. (2007b) Primary producing prokaryotic communities of brine, interface and seawater above the halocline of deep anoxic lake L'Atalante, Eastern Mediterranean Sea. ISME J 1:743-755

Zubkov MV, Burkhill PH, Topping J (2007) Flow cytometric enumeration of DNAstained oceanic planktonic protists. J Plankt Res 29:79-86

Zuendorf A, Behnke A, Bunge J, Barger K, Stoeck T (2006) Diversity estimates of microeukaryotes below the chemocline of the anoxic Mariager Fjord, Denmark. Fems Microbiol Ecol: 476-491 